\title{
Studies on Iron Embedded Polyesteramide Resin Derived from Melia-azedarach Seed Oil-A Renewable Resource
}

\author{
A. HASNAT ${ }^{1 *}$, M. NASEEM ${ }^{2}$ and S. A. AHMAD ${ }^{1}$ \\ 'Natural Product and Polymer Research Laboratory, Department of Chemistry, \\ G.F. College (M.J.P. Rohilkhand University), Shahajahanpur, U.P., 242001, India \\ ${ }^{2}$ Applied Chemistry Laboratory, University Polytechnic, Integral University Campus, \\ Shahjahanpur, U.P., 242001, India. \\ ${ }^{*}$ Corresponding author E-mail: hasnatgfc @ rediffmail.com \\ http://dx.doi.org/10.13005/ojc/320531
}

(Received: June 04, 2016; Accepted: August 13, 2016)

\begin{abstract}
Due to the depletion of petroleum oil reserves and the environmental issues both, efforts have made to utilize the renewable resources in the polymer synthesis now-a-days. Among the different renewable resources seed oils of different plants pay considerable attraction due to its unique properties. Melia azedarach is a medium sized tree largely cultivated throughout the country as a shadow tree. The seeds of the plant have approximately $40-w t \%$ non edible oil with sufficiently high unsaturation. In the present work, oil of the Melia azedarach seeds utilized in making iron embedded polyesteramide with the objective to provide satisfactory utilization of abundantly available raw material significantly going waste in every season. The physico-chemical characterization of the polymeric material and intermediates were carried out as per standard laboratory methods. The structural elucidation of the polymeric resin was carried out by spectral analyses. The film properties of the iron embedded polyesteramide were also investigated in different environments. The results show that the iron embedded polyesteramide derived from Melia azedrach show good physic-mechanical and corrosion resistance performances in different service conditions.
\end{abstract}

Keywords: Melia .azedarach seed oil, Iron-filled polyesteramide, coating material.

\section{INTRODUCTION}

Polyesteramide resins are amide modified alkyds contain both amide and ester linkages in the polymeric chain ${ }^{1-3}$. They have reported for improved characteristics over normal alkyds in terms of hardness, ease of drying and better resistance ability towards water vapor ${ }^{4-6 .}$ Therefore, these resins are largely used as a coating materials or binder for paints to protect the metals from environmental corrosion and wood from biological organisms ${ }^{7-8}$. Furthermore, incorporation of metals, metalloids and organic moieties like styrene, acrylates, methacrylates in the polymeric materials improve the performances 
like scratch hardness ${ }^{9}$, chemical resistivity ${ }^{10}$ as well as reduces the baking temperature required for curing notably. The primary raw material used for the synthesis of commercially important polymers has been petroleum for the last five decades ${ }^{11-12}$. However, the petroleum resources are going to deplete day by day, consequently it become costly due to scarcity. In recent years search for alternative renewable resources have been stimulated, which can be gown again and again ${ }^{1,2,13}$. Furthermore, their productivity can be raised as per demand by more plantations.

Among the different renewable resources, vegetable oils are widely used as an alternative sustainable resource for petroleum based monomers, in the synthesis of different kinds of polymers ${ }^{1,314,15}$. Numerous vegetable oils like sunflower, coconut soybean, linseed and castor have been extensively used for the syntheses low molecular weight polymers ${ }^{14-17}$. However, among these vegetable oils some are edible and other are also poses some medicinal values ${ }^{17}$. Therefore, it is required to explore the nature's blessings and utilized the non-edible and non-traditional seed oils in making value added polymeric materials which ultimately provide suitable utilization to them as well as reduce the pressure on traditional vegetable oils.

Melia azedarach tree yielded non edible seeds which contain about $40-$ wt $\%$ oil with appropriate percentage of unsaturated fatty acids ${ }^{18}$. Physico-chemical properties, especially high iodine value encourage us to utilized this vegetable oil in developing iron embedded polyesteramide with the view to provide more satisfactory utilization. In present work efforts made to utilize the seed oil of the Melia azedarach in making iron embedded polyesteramide resins with double objective utilization of non-conventional seed oil in making coating material and reduce the pressure on utilization of petrochemicals.

\section{EXPERIMENTAL}

\section{Materials}

Oil was extracted from air dried and crushed seeds of Melia azedarach tree (collected from the R.T.O. office compound, Shahjahanpur, India) through a soxhlet apparatus, using petroleum ether (boiling point range $60-80^{\circ} \mathrm{C}$ ) as a solvent. Phthalic acid, methanol, pyridine and chloroform were used of analytical grade (S.D.Fine Chemicals India). Ferric acetate (Rolex laboratory reagents, India) was used as received. Diethanolamine of analytical grade (S.D. Fine Chemicals, India) was distilled under pressure before use. Petroleum benzene, xylene (Fisher scientific, India) and were used without further purification.

\section{Syntheses}

\section{N, N-bis(2-hydroxyethyl) Melia azedarach oil fatty amide (HEMAFA)}

HMAFA was synthesized and characterized as per previously reported method ${ }^{19}$.

\section{Polyesteramide of HEMAFA and Phthalic acid (MAPEAP)}

MAPEAP was synthesized as per stepgrowth polymerization technique for fatty amide diol and dibasic acid ${ }^{15}$. HEMAFA and Phthalic acid in equiv-molar ratio along with $50 \mathrm{ml}$ xylene as a solvent were taken in a four- necked round bottom

Table 1: Physico-chemical, mechanical and chemical/corrosion resistance properties of Fe-MAPEAP polymeric resin

\begin{tabular}{|c|c|}
\hline Test & Fe-MAPEAP \\
\hline \multicolumn{2}{|l|}{ Physico-chemical analyses } \\
\hline Color value & 8.0 \\
\hline Specific gravity & 0.972 \\
\hline Refractive index & 1.509 \\
\hline lodine value & 30.8 \\
\hline \multicolumn{2}{|c|}{ Physico-mechanical properties } \\
\hline Bending test (1/8 in) & Passes \\
\hline Gloss at $45^{\circ}$ & 95 \\
\hline Impact resistance (Ib/in) & 200 \\
\hline Scratch hardness $(\mathrm{Kg})$ & 3.1 \\
\hline \multicolumn{2}{|c|}{ Chemical/corrosion resistance* } \\
\hline $\mathrm{H}_{2} \mathrm{O}$ (10 days) & $E$ \\
\hline $\mathrm{HCl}(3-w \mathrm{t} \%) 10$ days & $E$ \\
\hline $\mathrm{NaOH}(2-w t \%) 2 \mathrm{hrs}$ & $\mathrm{C}$ \\
\hline $\mathrm{NaCl}(3.5-w t \%) 10$ days & $E$ \\
\hline Xylene 10 days & $\mathrm{D}$ \\
\hline
\end{tabular}

${ }^{*} \mathrm{~A}=$ Film detached; $\mathrm{B}=$ Film partially detached; $\mathrm{C}=$ Loss in gloss; $\mathrm{D}=$ Slight loss in gloss; $\mathrm{E}=$ Unaffected 
flask attached with a Dean-stark trap, nitrogen inlet tube, thermometer and a mechanical stirrer. The Reaction mixture was heated at $180 \pm 5^{\circ} \mathrm{C}$ and maintained until the calculated amount of water was collected in the Dean-Stark trap. The progress of reaction was also monitored by taking acid value at regular intervals. After the completion of reaction, the reaction contents were allowed to cool at room temperature under stirring. The product was taken out from the reaction flask and excess of xylene was removed from the reaction mixture in a rotary vacuum evaporator.

\section{Synthesis of Iron embedded Polyesteramide from MAPEAP (Fe-MAPEAP)}

Iron was incorporated in MAPEAP by reacting the resin with ferric acetate $\left(\mathrm{CH}_{3} \mathrm{COO}\right)_{3} \mathrm{Fe}$ The aforementioned setup was used for the synthesis of Fe-MAPEAP. MAPEAP (0.050 mole) and $\left(\mathrm{CH}_{3} \mathrm{COO}\right)_{3} \mathrm{Fe}(0.006$ mole $)$ along with 50 $\mathrm{ml}$ xylene were palced in afore mentioned setup. The reaction contents were heated at the rate of $10^{\circ} \mathrm{C} /$ min upto $60^{\circ} \mathrm{C}$. This temperature was maintained for one hour, followed by an increase in temperature upto $160 \pm 5^{\circ} \mathrm{C}$ and was further maintained for 2 hours. TLC was used to monitor the progress of reaction. After the completion of reaction, the end product was allowed to cool down at room temperature and diluted in ether, then washed with 5 wt-\% aqueous $\mathrm{NaCl}$ solution. After washing, the product was dried over anhydrous sodium sulphate and the excess of solvent was removed in a rotary vacuum evaporator under reduced pressure to obtain the Fe-MAPEAP.

\section{Characterization}

Physic-chemical characterizations like refractive index, specific gravity, acid value, iodine value of polymeric material was determine as per standard reported laboratory methods ${ }^{8-10}$. Spectral analyses of polymer sample were used for the structural elucidation. FT-IR spectrum of the polymer sample was recorded on FT-IR spectrophotometer
(Perkin-Elmer) using a $\mathrm{NaCl}$ cell. ${ }^{1} \mathrm{H}-\mathrm{NMR}$ and ${ }^{13} \mathrm{C}$-NMR spectra were recorded on JEOL GSX 300 $\mathrm{MHz}$ FX-1000 spectrometer, using tetramethyl silane (TMS) as an internal reference, where as deuterated chloroform as a solvent.

\section{Preparation of coatings}

Fe-MAPEAP polymeric resin were applied on mild steel coupons, $70 \times 25 \times 1 \mathrm{~mm}$ size for physico-

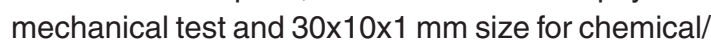
corrosion resistance test ${ }^{20}$. The mild steel strips were polished on various grade of silicon carbide papers, then washed with distilled water and finally degreased with alcohol and carbon tetrachloride. The $60-w t \%$ solution of Fe-MAPEAP polymeric resin was applied on these specimens' using brush technique ${ }^{20}$. Coated samples were baked for 5-35 minutes in an oven at different temperature (170$200^{\circ} \mathrm{C}$ ) to find out the optimum baking time and temperature. The best coatings were obtained by baking at $190^{\circ} \mathrm{C}$ for 15 minutes. Coating thickness was measured by Elcometer (345 digital coating thickness gauge). The coating thickness were found between 120-150 $\mu \mathrm{m}$. Flexibility (ASTMD 3281-84), scratch resistance (BS 3900) and impact resistance (IS: 101(Part 5/Sec. 3) of the coatings were also tested. Corrosion tests were done in water, acid (5-wt\% $\mathrm{HCl})$, alkali $(5-w t \% \mathrm{NaOH})$ and salt (3.5-wt\% $\mathrm{NaCl}$ ) by taking them in 3 inch diameter porcelain dishes and placing the coated samples in these dishes. Periodic investigation was carried out until the coating showed evidence of softening, loss in gloss or deterioration.

\section{RESULTS AND DISCUSSION}

Figure $1(a, b, c)$ illustrate the reaction schemes for the synthesis of HEMAFA, MAPEAP and Fe-MAPEAP. The MAPEAP was synthesized by the amidation of MASO with diethanol amine and then by the step-growth polymerization of HEMAFA with phthalic acid. The resulting MAPEAP

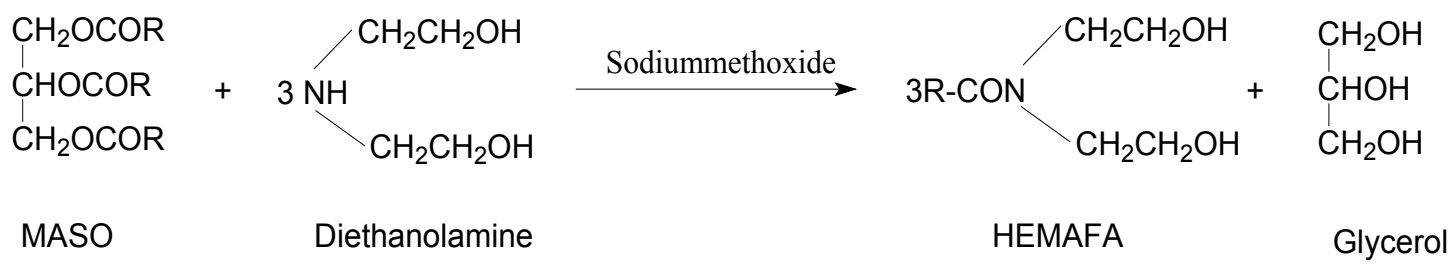

Fig. 1(a): Synthesis of HEMAFA 


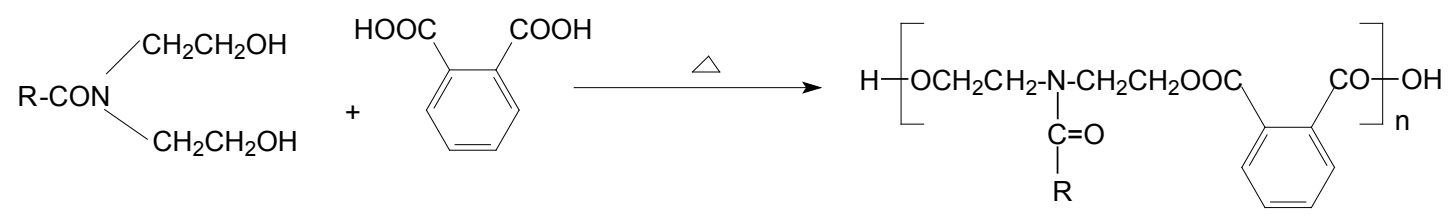

HEMAFA

Phthalic acid

MAPEAP

Fig. 1(b): Synthesis of MAPEAP

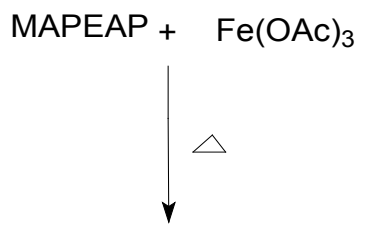

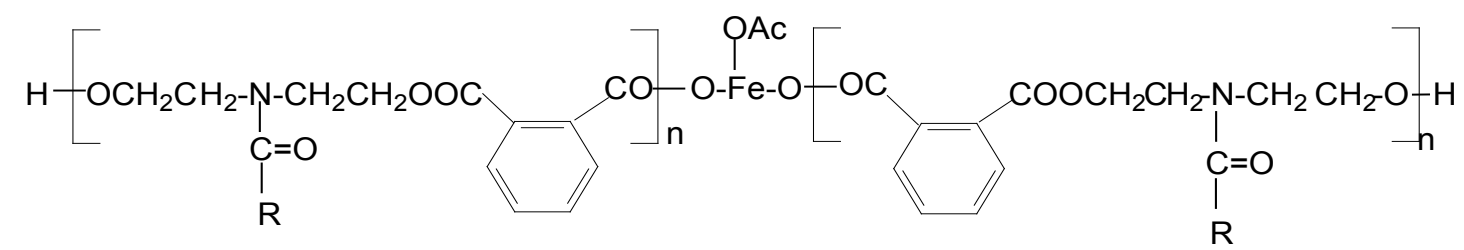

Fe-MAPEAP

Fig. 1 (c): Synthesis of Fe-MAPEAP

was then treated with $\left(\mathrm{CH}_{3} \mathrm{COO}\right)_{3} \mathrm{Fe}$ to obtain FeMAPEAP polymeric resin. The acid values of the reaction mixture decreases while the conversion of HEMAFA to MAPEAP and then MAPEAP to FeMAPEAP. This is due to the formation of repeating ester as well as iron carboxylate linkages during poly (condensation).

The various physico-chemical characterizations like specific gravity, refractive index, inherent viscosity, iodine value, acid value and saponification value of the developed resins were determined as per standard reported laboratory methods and summarized in Table 1.

The FT-IR spectrum of the Fe-MAPEAP shows the band of alcoholic group at $3490 \mathrm{~cm}^{-1}$ (broad band of a primary alcohol), $\mathrm{CH}_{2}$ asymmetric and symmetric stretching band at 2923 and $2856 \mathrm{~cm}^{-1}$ respectively. The bands for carbonyls of repeating ester and amide groups are observed at $1756 \mathrm{~cm}^{-1}$ and $1648 \mathrm{~cm}^{-1}$ respectively. The $\mathrm{CN}$ stretching band (C-N group) appears at $1464 \mathrm{~cm}^{-1}$. The C-O-C symmetric and asymmetric bands are observed at 1279 and $1289 \mathrm{~cm}^{-1}$. The band at $768.0 \mathrm{~cm}^{-1}$ is a characteristic of disubstituted benzene of a phthalic acid ${ }^{21}$.

The ${ }^{1}$ HNMR spectrum of Fe-MAPEAP Shows the peak at $\delta=0.88-0.92$ ppm for terminal methyl group. A broad peak of chain $\mathrm{CH}_{2}$ group appears at $\delta=1.28-1.3 \mathrm{ppm}$, protons of double bonded carbons appear at $\delta=5.3-5.40 \mathrm{ppm}$, where as aromatic protons are observed at $\delta=7.54-7.62$ ppm, supporting the structure of Fe-MAPEAP as shown in Figure $1 .{ }^{13} \mathrm{C}$-NMR spectrum shows the characteristic signal of carbonyl of iron corboxylate and repeating ester at $\delta=184.0 \mathrm{ppm}$ and $\delta=180.2$ ppm, confirm the formation of these linkages ${ }^{21}$. The additional signal such as carbonyl of amide appears at $\delta=176.0 \mathrm{ppm}$. Various ring carbons of benzene ring appear at $\delta=135.4, \delta=134.2, \delta=129.0 \mathrm{ppm}$. The peak for double bonded carbons of fatty amide appears at $\delta=129.8-130.0 \mathrm{ppm}$, different $\mathrm{CH}_{2}$ group of the 
fatty amide chain appear at $\delta=26.0-36.2 \mathrm{ppm}$, while terminal methyl group of fatty acid chain appears at $16.2 \mathrm{ppm}$.

\section{Coating properties}

Coatings of Fe-MAPEAP were developed by brush technique on the required size coupons. The developed coatings were baked at different temperatures $\left(170-220^{\circ} \mathrm{C}\right)$ and time (10-30 mints) to obtain the optimum baking temperature and time at which coatings show best film properties. The optimum baking temperature and time for the Fe-MAPEAP polymeric resin was found $190^{\circ} \mathrm{C}$ and 15 minutes.

Coatings of Fe-MAPEAP were passing the bending test on 1/8 inch conical mandrel; no visual cracks were seen, like the coating materials of other vegetable oils ${ }^{7,9}$. Coatings of Fe-MAPEAP show remarkably high values for scratch hardness and impact resistance, reasonably due to incorporation of iron, which increase the chain length of polymer, ultimately cohesive forces among the polymer chains. The presences of iron in the backbone of the polymer chain also improve the adhesion between polymeric chains and metal surface and also increase the sites for secondary bonding. The Table 1 indicates that the coatings of Fe-MAPEAP also show the good protection ability in water, acid solutions and salty environment. These are reasonably due to the high cross-linking density and adhesion of the polymeric resins towards metal surface ${ }^{3}$.

\section{CONCLUSIONS}

The synthesis of Fe-MAPEAP from Melia azedarach seed oils provides a more profitable utilization of non-traditional, non-edible and renewable resource. The synthesize resin was characterized by spectral studies as well as by physico-chemical analyses. The physico-mechanical performances and chemical/corrosion resistance abilities of Fe-MAPEAP were also investigated. The study concludes that the synthesis of Fe-MAPEAP resin provides a fruitful route for the utilisation of Melia azedarach seed oil, rot away in every season.

\section{ACKNOWLEDGEMENTS}

The authors are thankful to authorities of G.F. College for providing necessary facilities. Dr. M. Naseem is grateful to the Prof. S. W. Akhtar, Learned Vice-Chancellor, Integral University, Lucknow

\section{REFERENCES}

1. Ansari, S. H., Imran G., Naseem M., Ahmad, S. A. and Hasnat, A. Orient. J. Chem. 2012, 28, 607

2. Ansari, S. H., Naseem M., Hasnat, A. and Ahmad, S. A. Biosici. Biotech. Res. Asia, 2011, 8, 829.

3. Ahmad, S., Ashraf, S. M., Hasnat, A., Yadav, S. and Jamal, A. J. Appl. Polym. Sci. 2001, 82, 1856.

4. Imran, G., Ahamad, S. and Ahmad S. A. Orient. J. Chem. 2015, 31, 53

5. Dutta, S. and Karak, N. Prog. Org. Coat. 2001, 53,147.

6. Zafar, F., Ashraf, S. M., Ahmad, S. Prog. Org. Coat. 2004, 51, 250.

7. Mahapatra, S. S. and Karak, N. Prog. Org. Coat. 2004, 51, 103.

8. Ahamad, S., Imran, G., Ahmad, S.A. and
Hasnat, A. Orient. J. Chem. 2015, 31, 1169.

9. Ahmad, S., Ashraf, S.M., Hasnat, A. and Noor, A. Indian J. of Chem. Technol. 2001, 8, 176.

10. Ahamad, S., Ahmad, S. and Hasnat, A. Mater. Sci. Res. Ind. (In press)

11. Ahmad, S., Ahmad, S. and Agnihotri S. A. Bull. Mater. Sci. 2007, 30, 31.

12. Weiss, K. D. Prog. Polym. Sci. 1997, 22, 203.

13. Meier, M. A. R., Metzger, J.O., and Schubert, U. S. Chem. Soc. Rev. 2007, 36, 1788.

14. Samarth, N. B. and Mahanwar, P. A. Open J. Org.Polym. Mater. 2015, 5, 1.

15. Islam, M. R., Beg, M. D. H. and Jamari, S. S., J. Appl. Polym. Sci. 2014, 131, 40787.

16. Olufunke, A. C. Nova J. Eng. Appl. Sci. 2014, $2,1$. 
17. Patel,V. C., Varughese, J., Krishnamoorthy, P. A., Jain, R. C., Singh, A. K. and Ramamoorty, M. J. Appl. Polym. Sci. 2008, 107, 1724.

18. Ambasta S. P., The Useful Plants of India, CSIR, India 1994.

19. Imran, G., Ahamad, S.,Altaf.I and Ahmad S. A.Chemical Science Transactions. 2015, 4, (4), 1007
20. Ahmad, S., Ashraf, S. M., Naqvi, F., Yadav, S. and Hasnat A. Prog. Org. Coat. 2003, 47 95.

21. Silverstein, R. M., Bassler, G. C. \& Morril, T. C., Spectroscopic Identification of Organic Compounds, $5^{\text {th }}$ edn., John Wile y \& Sons, New York, 1991. 